\title{
Early life microbial exposure and fractional exhaled nitric oxide in school-age children: a prospective birth cohort study
}

Lidia Casas ${ }^{1,2,3^{*}}$, Christina Tischer $^{4}$, Inge M Wouters ${ }^{5}$, Maties Torrent ${ }^{6}$, Ulrike Gehring ${ }^{5}$, Raquel Garcia-Esteban ${ }^{1,2,3}$, Elisabeth Thiering ${ }^{4}$, Dirkje S Postma ${ }^{7}$, Johan de Jongste ${ }^{8}$, Henriëtte A Smit ${ }^{9}$, Alícia Borràs-Santos ${ }^{1,2,3}$, Jan-Paul Zock ${ }^{1,2,3}$, Anne Hyvärinen $^{10}{ }^{\text {, Joachim Heinrich }}{ }^{4}$ and Jordi Sunyer ${ }^{1,2,3,11}$

\begin{abstract}
Background: Inflammation is a key factor in the pathogenesis of respiratory diseases. Early life exposure to microbial agents may have an effect on the development of the immune system and on respiratory health later in life.

In the present work we aimed to evaluate the associations between early life microbial exposures, and fractional exhaled nitric oxide (FeNO) at school age.

Methods: Endotoxin, extracellular polysaccharides (EPS) and $\beta(1,3)-D-g l u c a n$ were measured in living room dust collected at 2-3 months of age in homes of participants of three prospective European birth cohorts (LISA, $n=182$; PIAMA, $n=244$; and INMA, $n=355$ ). Home dampness and pet ownership were periodically reported by the parents through questionnaires. FeNO was measured at age 8 for PIAMA and at age 10/11 for LISA and INMA.

Cohort-specific associations between the indoor microbial exposures and FeNO were evaluated using multivariable regression analyses. Estimates were combined using random-effects meta-analyses.

Results: FeNO at school age was lower in children exposed to endotoxin at age $2-3$ months ( $\beta-0.05,95 \%$ confidence interval $(\mathrm{Cl})-0.10 ;-0.01)$ and in children with reported dog ownership during the first two years of life (GM ratio 0.82 , Cl 0.70-0.96). FeNO was not significantly associated with early life exposure to EPS, $\beta(1,3)$-D-glucan, indoor dampness and cat ownership.

Conclusion: Early life exposure to bacterial endotoxin and early life dog ownership are associated with lower FeNO at school age. Further studies are needed to confirm our results and to unravel the underlying mechanisms and possible clinical relevance of this finding.
\end{abstract}

Keywords: Fractional exhaled nitric oxide, Endotoxin, Extracellular polysaccharides, $\beta(1,3)-\mathrm{D}$-glucan, Pets, Dampness, Indoor, Children, Cohort study

\section{Background}

The first years of life may be a crucial period for the development of the immune system and the onset of allergic and respiratory disorders [1,2]. In the last decade, numerous studies assessed associations between measured microbial agents and related indoor factors and reported

\footnotetext{
*Correspondence: Icasas@creal.cat

'Centre for Research in Environmental Epidemiology (CREAL), Barcelona, Spain

${ }^{2}$ Hospital del Mar Medical Research Institute (IMIM), Barcelona, Spain Full list of author information is available at the end of the article
}

respiratory and allergic outcomes in children [3-13]. Only few studies measured early-life microbial exposures and investigated health effects prospectively. They found that exposure to high levels of endotoxin in the first months of life may reduce the risk of eczema in infancy [7]. However, findings regarding wheezing and asthma are inconsistent $[5,6,14]$. Regarding indoor factors associated with higher indoor microbial agents levels, previous studies observed that early life exposure to indoor mould and dampness increases the risk of asthma [15-17]. However, the direction of the associations between early life exposure to pet ownership and

\section{Ciomed Central}


atopy, wheezing and asthma is ambiguous. Some studies found that the presence of a dog in the home during early life attenuated TNF- $\alpha$ production [18] and had a protective effect on atopy and wheezing $[19,20]$. Other studies observed positive or non-significant associations between home exposure to cats or dogs and atopy, respiratory symptoms and asthma [21-24]. In addition, a systematic review suggested no association with dog ownership with large heterogeneity across studies [25].

Inflammation is a key factor in the pathogenesis of respiratory diseases and FeNO is considered to be a noninvasive biomarker that is associated with eosinophilic airway inflammation [26-28]. High levels of NO in the airways are associated with asthma and other respiratory disorders [29] and with respiratory symptoms and atopy in children [30-33]. In epidemiological studies, using FeNO has the advantage that it is a continuous and easily measureable variable, as well as an objective variable, in contrast to self-reported categorical variables. Several epidemiologic studies showed associations between environmental exposures such as air pollution [34,35], polycyclic aromatic hydrocarbons [36], indoor allergens [37] and other indoor factors [38] and FeNO. However, the effects of early life exposure to microbial agents and indoor factors on FeNO have not been explored. In our study, we assessed the associations of microbial agents (endotoxin, EPS and $\beta(1,3)$-D-glucans) in house dust, reported dampness and pet ownership early in life with FeNO in school-aged children in three European birth cohorts participating in the European HITEA project (Health Effects of Indoor Pollutants: Integrating microbial, toxicological and epidemiological approaches).

\section{Methods}

\section{Study population and design: description of the three birth cohorts}

As part of the European HITEA project, the present study includes information from three ongoing European birth cohorts that started between 1996 and 1999: LISA (influence of life-style factors on the development of the immune system and allergies in East and West Germany) in Germany [39], PIAMA (Prevention and Incidence of Asthma and Mite Allergy) in the Netherlands [40]. and INMA (INfancia y Medio Ambiente [Environment and Childhood]) in Spain [41]. Written informed consent was obtained from all parents and the studies were approved by the local ethics committees in each cohort region: the Ethik-Kommission der Bayerischen Landesärztekammer for LISA, the Centrale Commissie Mensgebonden Onderzoek (CCMO), the Medisch Ethische Commissies of the University Medical Center Utrecht, the Erasmus Medical Center Rotterdam, and the Academisch Ziekenhuis Groningen for PIAMA and the Ethics Committee of the Institut Municipal d'Investigació Mèdica - Parc de Salut Mar for INMA.
A description of the participating birth cohorts is given in the Additional file 1 and in the paper describing the exposures under study [42]. The present study includes children with measured endotoxin, EPS and/or $\beta(1,3)$-D-glucans in living room dust collected during early life and FeNO measurements at school age (182 from LISA, 244 from PIAMA, and 355 from INMA).

\section{Fractional exhaled Nitric Oxide (FeNO)}

FeNO was measured in LISA at 10 years of age, in PIAMA at 8 years of age [43] and in INMA at 10 to 13 years of age, according to the American Thoracic Society guidelines [44] using the NIOX $\mathrm{MINO}^{\circ}$ in LISA and INMA and the NIOX analyser (Aerocrine, Solna, Sweden; http://www.aerocrine.com) in PIAMA. In LISA and INMA children were refrained from eating or drinking one hour before the measurement. They were asked to inhale to near-total lung capacity through the NIOX $\mathrm{MINO}^{\circ}$, and to exhale immediately at a constant flow rate of $50 \mathrm{~mL} / \mathrm{sec}$ until a NO plateau of at least 3 seconds could be identified during an exhalation of at least 6 seconds. Measurements in both cohorts were performed until a correct FENO measurement was displayed. If necessary, the FENO test was repeated to obtain one acceptable measurement.

In PIAMA, children were instructed to inhale to neartotal lung capacity through a NO scrubber (Dräger combination filter, Dräger, Lübeck, Germany), integrated in the NIOX analyzer, and to exhale immediately at a constant flow rate of $50 \mathrm{~mL} /$ second, until a NO plateau of at least 2 seconds could be identified during an exhalation of at least 4 seconds. A maximum of 6 attempts were performed to obtain three acceptable FENO measurements. FENO in PIAMA is expressed as the average of the 3 measurements.

In the LISA cohort children who had taken any antiasthmatic or anti-inflamatory medication did not perform the test. In PIAMA and INMA the use of antiasthmatic medication (in the past 24 hours in INMA, in the past 48 hours in PIAMA) or anti-inflammatory medication (in the past 24 hours for INMA and PIAMA) was recorded. Four children in PIAMA and 49 in INMA had taken anti-asthmatic or anti-inflammatory medication. In the three birth cohorts, all values were above the LOD. Children did not have any active upper or lower respiratory tract viral infection on the day of the measurement.

\section{Dust collection, extraction and analyses}

Living room dust samples were collected at the child's age of 2-3 months in the homes of the participants, using vacuum cleaners equipped with ALK filterholders containing a paper filter and the date of sampling was recorded. Samples were collected on living room floors 
in LISA and PIAMA, and on living room sofa in INMA. Collected samples were stored at $-20^{\circ} \mathrm{C}$, and analyzed for microbial agents at in the Institute for Risk Assessment Sciences (IRAS, Utrecht, NL). Endotoxin has been determined with the Limulus Amebocyte Lysate test and glucan and EPS with specific enzyme immunoassays as in previous house dust analyses [45]. Levels were expressed in Endotoxin Units (EU), EPS Units (EPSU), and $\mu \mathrm{g}$ of $\beta(1,3)$-D-glucan per $\mathrm{mL}$, with as lower limit of detection (LOD) $10 \mathrm{EU} / \mathrm{mL}$ (2 EU/mL in INMA), 180 $\mathrm{EPSU} / \mathrm{mL}$, and $2 \mu \mathrm{g} / \mathrm{mL}$, respectively, and converted into concentrations in the original dust samples (in EU/mg, $\mathrm{EPSU} / \mathrm{mg}$ and $\mu \mathrm{g} / \mathrm{mg}$ ). Samples with non-detectable amounts of endotoxin, glucans and EPS were assigned a value of $2 / 3$ of the LOD. Detailed information on the dust collection, extraction and analyses and a description of the values below the LOD is shown elsewhere [42].

\section{Reported indoor factors: dampness at home and cat and dog ownership}

Questions about housing characteristics and potential exposures in the home environment were taken from questionnaires administered to the parents from birth to the child's age of 8 (PIAMA) and 10 years (LISA and INMA). Dampness or visible mould at home was reported by the parents at the child's ages of 3 months, 1 and 2 years in the three cohorts. We combined these data into a single binary exposure variable on ever reported dampness or visible mould during the first 2 years of life. Cat and dog ownership was reported at birth and at the child's ages of 1, 2, 4, 6 and 10 (8 in PIAMA) years in the three cohorts. For the statistical analyses, we computed separate 3-category variables for cat and for dog, describing the timing of the first cat/dog ownership. These variables indicated "Never" (no report of ownership), "Ever during the first 2 years of life" (at least one report of ownership in the first 2 years of life), and "Ever after the first 2 years of life, but not during the first 2 years of life" (at least one report of ownership after the first 2 years of life, but no report during the first 2 years) exposure.

\section{Potential confounders and effect modifiers}

The questionnaires administered during pregnancy or at birth and at the child's ages of 1, 2, 4, 6 and 10 (8 in PIAMA) years included socio-demographic, health and environmental data such as: parental education (low, medium or high); medical data of the parents; parental smoking; housing characteristics including the location of the home (area population density) and moving to another home. Information about the child's allergic and respiratory health was obtained from parental reports of hay fever, rhinitis, eczema, wheezing, asthma medication and doctor diagnosed asthma. Two new variables, one for asthma and another including reported allergies, were computed and considered as potential effect modifiers. Asthma cases were children with a positive answer to two out of three of the following questions: doctor diagnosed asthma; wheezing; asthma medication, in any year between 4 and10 ( 8 in PIAMA) years of age. Allergy cases were defined as children with at least one positive answer to questions on hay fever, rhinitis and eczema in any year between 4 and 10 (8 in PIAMA) years of age. Atopy was assessed in $74 \%$ of the study population. Specific immunoglobulin $\mathrm{E}$ (sIgE) was measured in blood in the three cohorts at different time points: 10 years of age in LISA, 8 years of age in PIAMA and 4 years of age in INMA. In LISA, atopy was defined as sIgE of at least $0.35 \mathrm{kU} / \mathrm{l}$ for 'sx1 inhalant mixture' (timothy, rye, mugwort, house dust mite (Dermatophagoides pteronyssinus, Der p), cat, dog and mould mixture). In PIAMA, atopy was defined as sIgE of at least $0.35 \mathrm{kU} / \mathrm{l}$ for house dust mite (Der p), cat, dog, birch, Alternaria alternata and Dactylis glomerata. Finally, atopy in INMA was defined as $\operatorname{sgE} \geq 0.35 \mathrm{U} / \mathrm{mL}$ of IgE for Der $\mathrm{p}$, cat or grass/pollen. A list of all the potential confounders evaluated in this study is provided in the Additional file 1.

\section{Statistical analyses}

The distribution of the FeNO, endotoxin, EPS and glucan measurements was right-skewed and therefore their levels were natural log-transformed. Generalized additive models (GAM) [46] were used to assess the functional relationship between the concentrations of microbial agents and FeNO stratified per cohort and in cohortadjusted pooled analyses. With descriptive purposes, we computed quartiles of endotoxin concentrations and tertiles of EPS and glucan concentrations and added a < LOD category that included samples with microbial agents measurements below the limit of detection. These variables were calculated to show the distribution of FeNO according to the levels of microbial agents. A description of the quantiles is shown in Table E1 of the Additional file 1. Nevertheless, the main analyses are conducted using the microbial agents concentrations as continuous variables.

To assess the adjusted associations between FeNO and the exposure variables by cohort, we performed multivariable linear regression models. Potential confounders were a-priori identified from the literature and selected based on their relationship with FeNO and the exposure variables in the present study (listed in the Additional file 1). The concentration of each microbial agent (endotoxin, EPS and glucans) and target indoor factor (dampness and cat and dog ownership) was included separately in the models. In order to facilitate interpretation, the resulting regression coefficients for categorical variables were back-transformed to their exponential $(\exp (\beta))$, yielding the ratio of the GM of 
FeNO of each exposure category vs the reference category. For continuous natural log-transformed variables, we present the coefficients $(\beta)$ in the tables. To facilitate the interpretation of these coefficients in the text, we transformed the coefficients to $\left(2^{\beta}-1\right)^{*} 100$. This transformation allows interpreting the coefficient as the percentage of increase in FeNO when doubling the dose of each microbial agent. In order to assess the possibility of effect modification of studied associations with the report of allergy and atopy, we included interaction terms between the report of allergy and atopy and the exposure variables and we performed stratified analyses. For additional sensitivity analyses, we excluded individuals that had taken anti-asthmatic or antiinflammatory medication during the 48 or 24 hours prior to the FeNO measurement.

Finally, we performed random-effects meta-analyses including the three cohort-specific estimates. We obtained combined GM ratios and their $\mathrm{CI}$ for each microbial agent and indoor factor. Potential heterogeneity between cohorts was examined using the Cochran Q statistics ( $\mathrm{p}$-value < 0.05). Data analysis was conducted with STATA SE 10.0 statistical software (Stata Corporation, College Station, TX, USA).

\section{Results}

A description of the socio-demographic, respiratory health and indoor exposure characteristics of the HITEA participants included and not included in this study is shown in Table 1. Children included were not different from those not included regarding most characteristics. Across the participating cohorts, we observed statistically significant differences for all variables except sex and doctor diagnosed asthma. Higher parental education was observed in the LISA cohort, higher asthma prevalence in PIAMA and higher smoking report in INMA compared to the other cohorts. The percentage of

Table 1 Description of the HITEA project participants, not included and included in the study

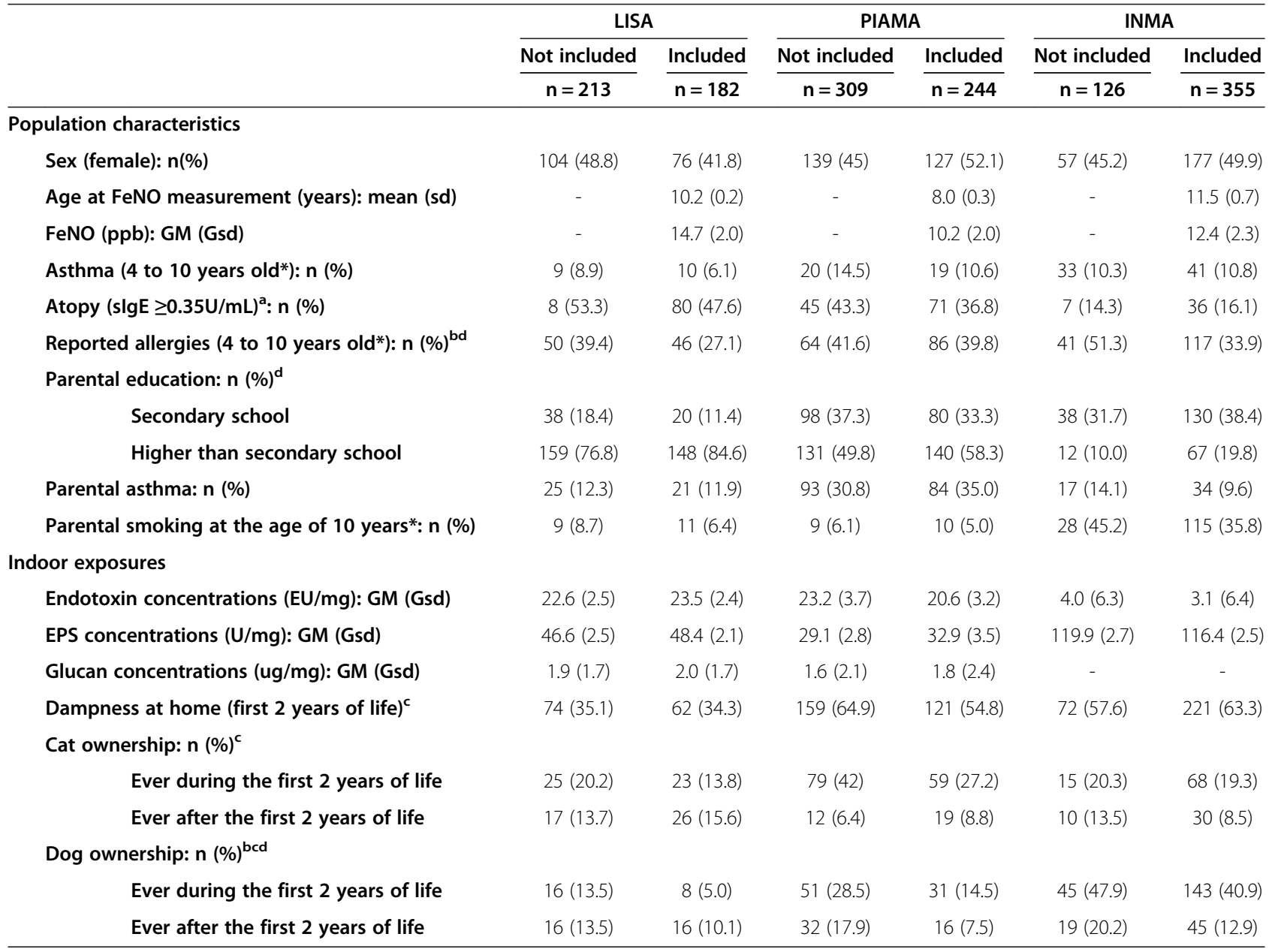

sd: standard deviation; GM: geometric mean; Gsd: geometric standard deviation; FeNO: fractional exhaled nitric oxide; Reported allergies: eczema, rhinitis or hay fever.

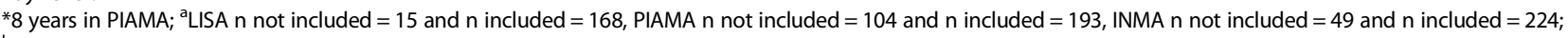
${ }^{b} p$-value $<0.05$ of the difference between included and not included in LISA; ${ }^{c} p$-value $<0.05$ of the difference between included and not included in PIAMA; ${ }^{d} p$-value $<0.05$ of the difference between included and not included in INMA. 
children with allergy report was higher in the PIAMA cohort whereas the age at FeNO measurement and FeNO was lower, the percentage of children with atopy was higher in LISA, where children were older at the moment of sIgE measurements (10 years old). Regarding the exposure variables, in INMA, endotoxin concentrations were lower and the prevalence of dampness and dog ownership in the first two years of life was higher. Cat ownership in the first two years of life was higher in PIAMA.

Geometric means of FeNO were lower in individuals classified in the highest endotoxin quartile in INMA, FeNO was lower in the mid tertile of EPS in LISA and INMA and similar trends were observed for glucans in LISA. Children exposed to cats and to dogs in the first two years had lower FeNO, except for cats exposure in LISA. However the differences were not statistically significant ( $\mathrm{p}$-values $\geq 0.05$ ) (Table 2).

Sex, age at FeNO measurement, asthma, reported allergies, indoor smoking and parental education were associated with FeNO after mutual adjustment ( $\mathrm{p}$-values < 0.05 ) and thus included in the multivariate models. Parental education was also associated with the levels of indoor microbial agents, asthma and indoor smoking with pet ownership, and indoor smoking was additionally associated with reported dampness.

The smoothed association between FeNO and the microbial agents concentrations, per cohort and combined, showed that the associations were linear ( $\mathrm{p}$-values $>0.05$ in all cases, Figure 1). The combined random-effects adjusted coefficients for microbial agents concentrations were statistically significant for endotoxin, showing a $3.7 \%$ decrease in FeNO when doubling the dose of endotoxin $(\beta=-0.05$; $95 \%$ CI:-0.10; -0.01). In addition, combined random-effects adjusted GM ratios of FeNO were lower for individuals with reported dog ownership during the first 2 years of life. Association estimates for EPS, glucan, dampness and cat ownership were not statistically significant ( $p$-values $\geq 0.05$ ). $\mathrm{P}$-values for heterogeneity were above 0.1 in all cases (Table 3). These associations were adjusted for sex, age at FeNO measurement, asthma, parental indoor smoking at the time of the FeNO measurement, and parental education. Models including microbial agents measurements were additionally adjusted for season of dust sampling. Additional adjustment for other potential confounders such as season of FeNO measurement, asthma or antiinflammatory medication prior to the FeNO measurement, outdoor $\mathrm{NO}_{2}$ at school age or ever moving to another home did not modify the effect estimates. Additional adjustment for atopy resulted in an attenuation of the effects. Also, the effect estimates for endotoxin and early life pet ownership became statistically nonsignificant. The effect estimates for endotoxin and early life dog ownership after these additional adjustments are shown in Table E2 in the Additional file 1.
Table 2 Description of the FeNO (ppb) according to the asthmatic status and exposure per cohort

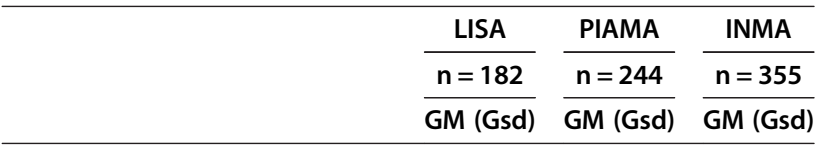

Asthma

$\begin{array}{llll}\text { No } & 13.7(1.9) & 10.4(1.9) & 11.3(2.1)\end{array}$

Yes $\quad 30.3(2.3) \quad 13.4(2.0) \quad 27.3(3.0)$

Endotoxin concentrations (EU/mg)

$12.6(1.4) \quad 7.8(1.5) \quad 12.3(2.4)$

Q2 (>3.54-12.4 EU/mg)

$17.2(1.9) \quad 11.5(2.2) \quad 13.0(2.2)$

Q3 (>12.4-30.6 EU/mg)

$14.3(2.0) \quad 10.1(1.9) \quad 11.8(2.1)$

Q4 (>30.6 EU/mg)

$14.4(2.0) \quad 9.7(1.8) \quad 11.5(2.2)$

EPS concentrations $(\mathrm{U} / \mathrm{mg})$

$<$ LOD

$14.2(2.3) \quad 9.5(2.0) \quad 10.4(1.8)$

T1 (<42 U/mg)

$15.2(2.0) \quad 10.6(2.0) \quad 11.8(2.3)$

T2 (>42-101 U/mg)

$13.8(1.9) \quad 9.9(1.9) \quad 12.1(2.1)$

T3 (>101 U/mg)

$16.2(2.2) \quad 12.5(1.8)$

$13.2(2.4)$

Glucan concentrations (ug/mg)

$<$ LOD

T1 $(<1.55 \mu \mathrm{g} / \mathrm{mg})$

$\begin{array}{cc}- & 9.4(2.1) \\ 15.8(2.0) & 10.9(1.9)\end{array}$

T2 (>1.55-2.35 $\mu \mathrm{g} / \mathrm{mg})$

$13.6(1.9) \quad 10.3(1.9)$

T3 (>2.35 $\mu \mathrm{g} / \mathrm{mg})$

$15.4(2.1) \quad 10.7(1.8)$

Dampness at home

Never

Ever during the first 2 years of life

$14.9(2.0) \quad 10.7(1.9) \quad 12.9(2.3)$

$14.3(2.1) \quad 10.0(2.0) \quad 12.1(2.3)$

Cat ownership

Never

$15.5(2.0) \quad 10.6(1.9) \quad 12.7(2.3)$

Ever during the first 2 years

of life

Ever after the first 2 years of life

$16.1(2.1)$

$9.7(1.8)$

$10.8(2.2)$

Dog ownership

Never

$15.1(2.0) \quad 10.5(2.0) \quad 13.3(2.4)$

Ever during the first 2 years

$13.4(1.6)$

$9.0(1.8)$

$11.6(2.3)$ of life

Ever after the first $\mathbf{2}$ years of life $\quad 15.5(1.6) \quad 10.9(2.1) \quad 12.3(2.1)$

GM: geometric mean; Gsd: geometric standard deviation; Q: quartile; T: tertile; EPS: extracellular polysaccharides; <LOD: below the limit of detection.

The association estimates obtained for each exposure variable were homogeneous across cohorts (heterogeneity p-values $\geq 0.05$ ). Stratification by parental report of child allergy did not show significant differences (see Table E3 in the Additional file 1). Moreover, adjusted GM ratios for the non-asthmatic population (Table E4 in the Additional file 1) were similar to those presented in Table 3. Finally, the exclusion of individuals who had taken anti-asthmatic or anti-inflammatory medication in the 48 or 24 hours previous to the FeNO measurement did not modify our results. 


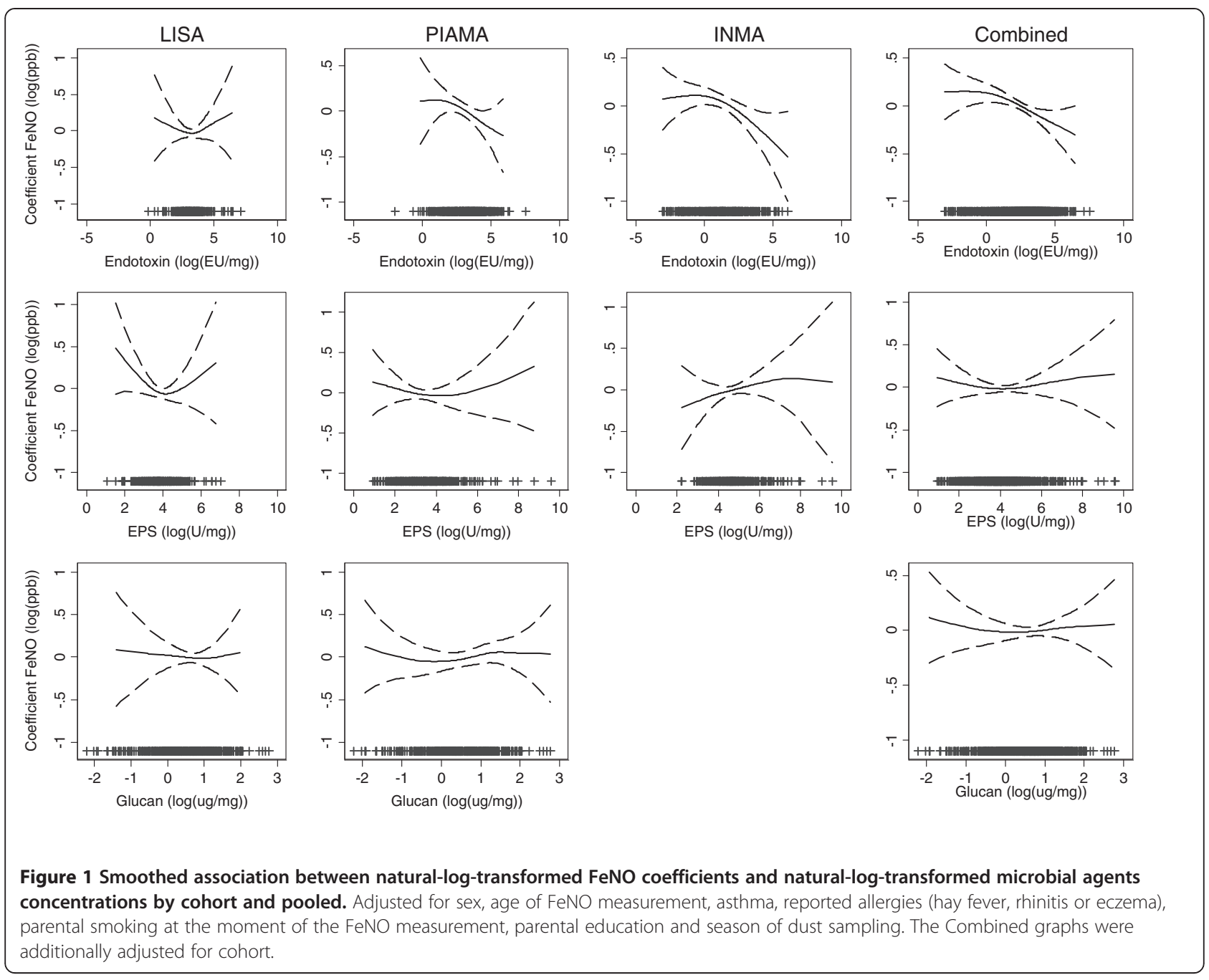

\section{Discussion}

Higher endotoxin concentrations and presence of dogs in the home during early life were associated with lower FeNO at school age. We investigated the association of FeNO as a potential biomarker of eosinophilic airway inflammation and microbial exposure variables, independently of any association with asthma or atopy. Our results do not suggest association with disease, but pertain to potential long-term effects of early life exposures on the immune system. Experimental animal studies previously showed that endotoxin and allergen exposure during pregnancy may modulate airway inflammation in offspring later in life, resulting in reduced allergeninduced immune and airway responses [47,48].

We observed that endotoxin exposure levels and dog ownership early in life were associated with lower FeNO. No associations were found for EPS and glucan exposure, cat ownership and reported home dampness. This is in line with previous epidemiological studies focusing on the health effects of residential exposure to microbial agents and pets in children, evaluating associations with respiratory symptoms, asthma and atopy. Most previous studies reported that endotoxin may protect against allergen sensitization, atopic eczema, wheezing and asthma later in life $[6,7,49,50]$. Regarding the exposure to fungal agents such as EPS or glucans, our study did not find statistically significant associations with FeNO. These results are in line with those obtained in previous studies on the association of EPS and glucan levels with respiratory symptoms $[6,21]$. However, previous studies have reported increased risks of asthma during childhood in association with mould exposure [15-17]. In our study, we did not find an association between early life reports of home dampness and FeNO at school age. The lack of associations in our study could be explained by the fact that our exposure was parental-reported dampness and not objective observation. However, results on previous studies regarding early life exposure to dogs are 
Table 3 FeNO adjusted associations with natural-log-transformed microbial agent concentrations, reported home dampness and pet ownership

\begin{tabular}{|c|c|c|c|c|c|c|}
\hline & \multirow[b]{2}{*}{ LISA } & \multirow[b]{2}{*}{ PIAMA } & \multirow[b]{2}{*}{ INMA } & \multicolumn{3}{|c|}{ Combined (random effects) } \\
\hline & & & & Total & Not reported allergies & Reported allergies \\
\hline & $\beta(95 \% \mathrm{Cl})$ & $\beta(95 \% \mathrm{Cl})$ & $\beta(95 \% \mathrm{Cl})$ & $\beta(95 \% \mathrm{Cl})$ & $\beta(95 \% \mathrm{Cl})$ & $\beta(95 \% \mathrm{Cl})$ \\
\hline \multicolumn{7}{|l|}{ Microbial agents concentrations } \\
\hline Endotoxin (log(EU/mg)) & $0.01(-0.11 ; 0.13)$ & $-0.08(-0.17 ; 0.01)$ & $-0.06(-0.11 ; 0.00)$ & $-0.05(-0.10 ;-0.01)$ & $-0.06(-0.11 ;-0.01)$ & $-0.06(-0.14 ; 0.03)$ \\
\hline EPS $(\log (\mathrm{U} / \mathrm{mg}))$ & $-0.03(-0.16 ; 0.11)$ & $0.02(-0.07 ; 0.11)$ & $0.06(-0.05 ; 0.17)$ & $0.02(-0.04 ; 0.08)$ & $0.07(0.00 ; 0.15)$ & $0.08(-0.05 ; 0.20)$ \\
\hline \multirow[t]{2}{*}{ Glucan $(\log (\mu \mathrm{g} / \mathrm{mg}))$} & $-0.07(-0.28 ; 0.15)$ & $0.02(-0.10 ; 0.13)$ & - & $0.00(-0.10 ; 0.10)$ & $0.00(-0.21 ; 0.21)$ & $0.04(-0.15 ; 0.24)$ \\
\hline & GM ratio $(95 \% \mathrm{Cl})$ & GM ratio $(95 \% \mathrm{Cl})$ & GM ratio $(95 \% \mathrm{Cl})$ & GM ratio $(95 \% \mathrm{Cl})$ & GM ratio $(95 \% \mathrm{Cl})$ & GM ratio $(95 \% \mathrm{Cl})$ \\
\hline \multicolumn{7}{|l|}{ Dampness at home } \\
\hline Never & 1 & 1 & 1 & 1 & 1 & 1 \\
\hline Ever during the first 2 years of life & $1.01(0.80-1.26)$ & $0.89(0.73-1.1)$ & $1.03(0.85-1.24)$ & $0.97(0.87-1.10)$ & $0.93(0.81-1.06)$ & $1.14(0.8-1.63)$ \\
\hline \multicolumn{7}{|l|}{ Cat ownership } \\
\hline Never & 1 & 1 & 1 & 1 & 1 & 1 \\
\hline Ever during the first 2 years of life & $0.97(0.71-1.33)$ & $0.89(0.70-1.13)$ & $0.83(0.65-1.06)$ & $0.89(0.76-1.03)$ & $0.98(0.78-1.22)$ & $0.72(0.51-1.04)$ \\
\hline Ever after the first 2 years of life & $0.87(0.64-1.19)$ & $0.96(0.65-1.43)$ & $1.22(0.88-1.69)$ & $1.01(0.82-1.24)$ & $1.11(0.90-1.37)$ & $0.83(0.52-1.32)$ \\
\hline \multicolumn{7}{|l|}{ Dog ownership } \\
\hline Never & 1 & 1 & 1 & 1 & 1 & 1 \\
\hline Ever during the first 2 years of life & $1.04(0.65-1.68)$ & $0.89(0.66-1.20)$ & $0.75(0.62-0.92)$ & $0.82(0.70-0.96)$ & $0.88(0.74-1.04)$ & $0.69(0.51-0.94)$ \\
\hline Ever after the first 2 years of life & $0.83(0.57-1.21)$ & $1.18(0.80-1.76)$ & $1.00(0.75-1.33)$ & $0.99(0.81-1.21)$ & $1.02(0.82-1.27)$ & $1.28(0.5-3.29)$ \\
\hline
\end{tabular}

Adjusted for sex, age of FeNO measurement, asthma, reported allergies, parental smoking at the moment of the FeNO measurement, and parental education. Models including endotoxin, EPS and glucan
measurements were additionally adjusted for season of dust sampling. Models stratified by reported allergies were not adjusted for reported allergies. All the heterogeneity tests were not significant ( $p$-values $\geq 0.05$ ). 
in line with our findings. Dog ownership was suggested to be inversely associated with allergic sensitization and respiratory symptoms $[18,19,50]$.

Asthma and atopy are known to be associated with high FeNO in children [31,51,52]. Moreover, children with persistent and late onset wheezing phenotypes are more likely to show higher FeNO at school age [30] and have higher risk of atopy and asthma [53,54]. FeNO is a test that may be used to support the diagnosis of asthma, and its role in asthma monitoring remains to be defined [55]. The association between the biochemical events involved in the release of NO in the airways and the inflammatory mechanisms needs to be further studied [56], but, at present, FeNO is, a extensively studied biomarker of airway inflammation and its non-invasive nature makes it suitable for epidemiological studies $[27,44,55,57]$. In line with the previous studies, FeNO in our study was higher in asthmatic, allergic and atopic children. We did not find differences in the associations between endotoxin and dog exposures and FeNO according to the report of asthma or allergy. However, the additional adjustment for atopy resulted in a decrease in the magnitude of the effect estimate of both exposures on FeNO while the direction of the effect remained the same. In addition, we considered the possibility that the early life exposures evaluated in our study were associated with FeNO through an association with atopy and not through airway inflammation. The statistical analyses with atopy as outcome did not show significant associations between atopy and endotoxin concentrations or early life dog ownership (data not shown).

However, caution is required when interpreting the results including information on atopy. Specific IgE levels in blood were not available in $26 \%$ of our study population and they were measured at different time points in each cohort (at the age of the FeNO measurement in LISA and PIAMA and at 4 years of age in INMA).

Our longitudinal study is the first epidemiologic study assessing the long-term effects of early life exposure to indoor microbial agents and related indoor factors on FeNO measured at school age. Our study includes data from subpopulations of three European birth cohorts in three geographically spread locations and benefits from the availability of objective measurements of exposure during early life (2-3 months) and objective measurements of airway inflammation at school age, in addition to reported information periodically collected through questionnaires administered from pregnancy or birth to school age.

A few limitations must be considered when interpreting our results. The study populations involved in the HITEA project were selected differently depending on the cohort. Only subsamples of LISA and PIAMA cohorts were included in the project. Inclusion was based on the availability of dust samples. In LISA, children included in the present study never moved to another home since early life. In PIAMA, the HITEA project includes children from the intervention study (high risk children of allergic mothers). In addition, several differences existed between cohorts in subject characteristics and dust sampling and analyses. In descriptive analyses FeNO values and age were lowest in PIAMA, the cohort with the highest number of allergic children. Results from multivariable regression analyses showed that FeNO, after age- and reported allergy adjustment, were 40\% lower in INMA compared to PIAMA (GM ratio $=$ 0.6; 95\% CI: 0.4-0.9), and that FeNO in PIAMA children was not different from that in LISA children (GM ratio $=0.9$; 95\% CI: 0.7-1.2). Regarding dust sampling and analyses, INMA dust samples were taken from sofa instead of floor because of the lack of carpets or rugs in the homes of the Menorca island. Furthermore, INMA samples were extracted in borate buffered saline (BBS) for earlier analysis of house dust mite allergens, which is not the standard extraction fluid used for endotoxin analyses, additionally the lack of heat-extraction impeded glucan quantification from these samples.

Overall, the association estimates differed somewhat by cohort. This might be explained by differences in inclusion criteria, in participants characteristics and in dust sampling and analyses. For these reasons, we explored to what extent our results are driven by only one or two cohorts by performing sensitivity analyses where we excluded one cohort at a time from the metaanalysis. The results from this sensitivity analyses showed that the combined coefficients of endotoxin exposure and for early life dog ownership are statistically significant when excluding LISA from the meta-analyses but not significant when excluding PIAMA or INMA. Nevertheless, the magnitude and direction of the coefficients did not change. The number of individuals included in the LISA cohort is lower than in the other cohorts. Therefore, the lack of statistical significance in the estimates when including LISA and only one of the other participating cohorts may be related to the statistical power and with the narrow range of exposures in LISA. In addition, LISA homes were located in a high density area (Munich city) while in the PIAMA and INMA cohorts the density of the area where homes were located varied. The density of the area where participants live may influence their behaviour regarding pet ownership and the levels of indoor microbial agents. This may also explain the differences observed in the coefficients for endotoxin exposure and dog ownership.

Apart from the differences across cohorts, other limitations related with the associations between the exposures, the outcome and the respiratory symptoms and allergy should be considered. FeNO is associated with 
atopy and asthma $[26,27,31,51,52]$. On the other hand, asthma and atopy may be associated with early life exposure to microbial agents and related indoor factors $[5,6,15]$. In order to assess the possibility of effect modification by reported allergy or atopy, we included interaction terms between the exposure variables in the models and reported allergy and atopy. Associations for the interaction terms between reported allergy or atopy and endotoxin and dog ownership were not statistically significant ( $\mathrm{p}$-values $>0.1$ ). Moreover, stratified analyses did not show differences in the effect estimates according to the disease group. However, because of the limited power after stratification, these results must be cautiously interpreted.

Furthermore, dog ownership is associated with higher levels of indoor endotoxins. In order to evaluate the independent effects of these two indoor factors on FeNO, we calculated the mutually adjusted coefficients for dog ownership and endotoxin concentrations. These coefficients were not different from those shown in Table 3. Therefore, we may assume that the effects observed for the exposures to endotoxin and dog ownership on FeNO are independent.

Finally, because the differences in FeNO across the different levels of exposure were small we must consider the possibility that our findings are due to a statistical association without a biological basis. Nevertheless, the consistency between our findings with dog ownership only in the first two years of life and endotoxin exposure supports the biological basis of our findings.

\section{Conclusions}

Exposure to high concentrations of bacterial endotoxin in the first months of life and dog ownership during the first two years of life, but not exposure to fungal microbial agents or home dampness, was associated with lower FeNO at school age. Further studies are needed to assess how this association is biologically explained, and what the clinical relevance could be.

\section{Additional file}

Additional file 1: Additional description of the study population, methods and results.

\section{Abbreviations}

EPS: Extracellular polysaccharides; FeNO: Fractional exhaled nitric oxide; NO: Nitric oxide; GM: Geometric mean; Gsd: Geometric standard deviation; sd: standard deviation; Cl: 95\% confidence interval; EU: Endotoxin units; EPSU: Extracellular polysaccharides units; LOD: Limit of detection; BBS: Borate buffered saline.

\section{Competing interests}

The authors declare that they have no competing interests.

\section{Authors' contributions}

LC performed the statistical analyses and drafted the manuscript. LC, CT and IMW were responsible for the study design. RGE was the data manager. AH was the Principal Investigator of the HITEA project and JS was the Principal Investigator of this study within the HITEA project. All other authors critically reviewed the manuscript and approved the final version of the manuscript for submission. All authors read and approved the final manuscript.

\section{Acknowledgments}

The authors would like to acknowledge all parents of the children from the three participating cohorts for patiently answering the questionnaires, all the technicians who have coordinated the fieldwork and performed laboratory analysis. The nurses and staff from the Health Care Centres involved in the three birth cohorts for the administrative, technical, and material support. And last, but not least, we would like to acknowledge all the children involved in the LISA, PIAMA and INMA birth cohorts.

This work was supported by the European Commission as part of HITEA (Health Effects of Indoor Pollutants: Integrating microbial, toxicological and epidemiological approaches), Grant agreement no. 211488 under the Seventh Framework Programme, Topic ENV.2007.1.2.1.1. "Indoor air pollution in Europe: An emerging environmental health issue".

The LISAplus study was funded by the BMBF (Federal Ministry of Education and Research), the Helmholtz Center Munich and the UFZ Leipzig. The PIAMA study is supported by The Netherlands Organization for Health Research and Development; The Netherlands Organization for Scientific Research; The Netherlands Asthma Fund; The Netherlands Ministry of Spatial Planning, Housing, and the Environment; and The Netherlands Ministry of Health, Welfare, and Sport. The INMA-Menorca study was funded by Fondo de Investigacion Sanitaria, ISCIII, Ministerio de Sanidad y Servicios Sociales, Spain (Grants 97/0588, 00/0021-2, G03/176, Pl061756 and PS0901958), EC Contract QLK4-CT-2000-00263 and Fundacio Roger Torne (Barcelona, Spain).

\section{Author details}

${ }^{1}$ Centre for Research in Environmental Epidemiology (CREAL), Barcelona, Spain. ${ }^{2}$ Hospital del Mar Medical Research Institute (IMIM), Barcelona, Spain. ${ }^{3}$ CIBER Epidemiología y Salud Pública (CIBERESP), Barcelona, Spain. ${ }^{4}$ Helmholtz Zentrum München, German Research Centre for Environmental Health, Institute of Epidemiology I, Neuherberg, Germany. ${ }^{5}$ Institute for Risk Assessment Sciences, Division of Environmental Epidemiology, Utrecht University, Utrecht, The Netherlands. ${ }^{6}$ Area de Salud de Menorca, IB-SALUT, Menorca, Spain. ${ }^{7}$ Department of Pulmonology, GRIAC research institute, University of Groningen, University Medical Center Groningen, Groningen, The Netherlands. ${ }^{8}$ Department of Pediatrics, Division of Respiratory Medicine, Erasmus University Medical Center/Sophia Children's Hospital, Rotterdam, The Netherlands. ${ }^{9}$ Julius Center for Health Sciences and Primary Care, University Medical Center, Utrecht, The Netherlands. ${ }^{10}$ Department Environmental Health, National Institute for Health and Welfare, Kuopio, Finland. ${ }^{11}$ University Pompeu Fabra, Barcelona, Spain.

Received: 13 May 2013 Accepted: 22 November 2013

Published: 2 December 2013

\section{References}

1. Prescott SL, Macaubas C, Smallacombe T, Holt BJ, Sly PD, Holt PG: Development of allergen-specific T-cell memory in atopic and normal children. Lancet 1999, 353:196-200

2. Holt PG: Primary allergic sensitization to environmental antigens: perinatal $\mathrm{T}$ cell priming as a determinant of responder phenotype in adulthood. J Exp Med 1996, 183:1297-1301.

3. Braun-Fahrländer C, Riedler J, Herz U, Eder W, Waser M, Grize L, Maisch S, Carr D, Gerlach F, Bufe A, Lauener RP, Schierl R, Renz H, Nowak D, von Mutius E: Environmental exposure to endotoxin and its relation to asthma in school-age children. N Engl J Med 2002, 347:869-877.

4. Carlsten C, Ferguson A, Dimich-Ward H, Chan H, DyBuncio A, Rousseau R, Becker A, Chan-Yeung M: Association between endotoxin and mite allergen exposure with asthma and specific sensitization at age 7 in high-risk children. Pediatr Allergy Immunol 2011, 22:320-326.

5. Celedón JC, Milton DK, Ramsey CD, Litonjua AA, Ryan L, Platts-Mills TAE, Gold DR: Exposure to dust mite allergen and endotoxin in early life and asthma and atopy in childhood. J Allergy Clin Immunol 2007, 120:144-149.

6. Douwes J, van Strien R, Doekes G, Smit J, Kerkhof M, Gerritsen J, Postma D, de Jongste J, Travier N, Brunekreef B: Does early indoor microbial exposure reduce the risk of asthma? The Prevention and Incidence of 
Asthma and Mite Allergy birth cohort study. J Allergy Clin Immunol 2006, 117:1067-1073.

7. Gehring U, Bolte G, Borte M, Bischof W, Fahlbusch B, Wichmann HE, Heinrich J: Exposure to endotoxin decreases the risk of atopic eczema in infancy: a cohort study. J Allergy Clin Immunol 2001, 108:847-854.

8. Gehring U, Heinrich J, Hoek G, Giovannangelo M, Nordling E, Bellander T, Gerritsen J, de Jongste JC, Smit HA, Wichmann H-E, Wickman M, Brunekreef B: Bacteria and mould components in house dust and children's allergic sensitisation. Eur Respir J 2007, 29:1144-1153.

9. Gehring U, Strikwold M, Schram-Bijkerk D, Weinmayr G, Genuneit J, Nagel G, Wickens K, Siebers R, Crane J, Doekes G, Di Domenicantonio R, Nilsson L, Priftanji A, Sandin A, El-Sharif N, Strachan D, van Hage M, von Mutius E, Brunekreef B: Asthma and allergic symptoms in relation to house dust endotoxin: Phase Two of the International Study on Asthma and Allergies in Childhood (ISAAC II). Clin Exp Allergy 2008, 38:1911-1920.

10. lossifova $Y Y$, Reponen $T$, Bernstein DI, Levin L, Kalra H, Campo P, Villareal M Lockey J, Hershey GKK, LeMasters G: House dust (1-3)-beta-D-glucan and wheezing in infants. Allergy 2007, 62:504-513.

11. Schram-Bijkerk D, Doekes G, Douwes J, Boeve M, Riedler J, Ublagger E, von Mutius E, Benz MR, Pershagen G, van Hage M, Scheynius A, BraunFahrländer C, Waser M, Brunekreef B: Bacterial and fungal agents in house dust and wheeze in children: the PARSIFAL study. Clin Exp Allergy 2005, 35:1272-1278

12. Sordillo JE, Sharma S, Poon A, Lasky-Su J, Belanger K, Milton DK, Bracken $M B$, Triche EW, Leaderer BP, Gold DR, Litonjua AA: Effects of endotoxin exposure on childhood asthma risk are modified by a genetic polymorphism in ACAA1. BMC Med Genet 2011, 12:158.

13. Tischer C, Gehring U, Chen C-M, Kerkhof M, Koppelman G, Sausenthaler $S$, Herbarth O, Schaaf B, Lehmann I, Krämer U, Berdel D, von Berg A, Bauer CP, Koletzko S, Wichmann H-E, Brunekreef B, Heinrich J: Respiratory health in children, and indoor exposure to (1,3)- $\beta$-D-glucan, EPS mould components and endotoxin. Eur Respir J 2011, 37:1050-1059.

14. Park JH, Gold DR, Spiegelman DL, Burge HA, Milton DK: House dust endotoxin and wheeze in the first year of life. Am J Respir Crit Care Med 2001, 163:322-328.

15. Iossifova YY, Reponen T, Ryan PH, Levin L, Bernstein DI, Lockey JE, Hershey GKK, Villareal M, LeMasters G: Mold exposure during infancy as a predictor of potential asthma development. Ann Allergy Asthma Immunol 2009, 102:131-137.

16. Reponen T, Vesper $S$, Levin L, Johansson E, Ryan P, Burkle J, Grinshpun SA, Zheng S, Bernstein DI, Lockey J, Villareal M, Khurana Hershey GK, LeMasters $\mathrm{G}$ : High environmental relative moldiness index during infancy as a predictor of asthma at 7 years of age. Ann Allergy Asthma Immunol 2011, 107:120-126.

17. Tischer CG, Hohmann C, Thiering E, Herbarth O, Müller A, Henderson J, Granell R, Fantini MP, Luciano L, Bergström A, Kull I, Link E, von Berg A, Kuehni CE, Strippoli M-PF, Gehring U, Wijga A, Eller E, Bindslev-Jensen C, Keil T, Heinrich J: Meta-analysis of mould and dampness exposure on asthma and allergy in eight European birth cohorts: an ENRIECO initiative. Allergy 2011, 66:1570-1579

18. Lappalainen MHJ, Huttunen K, Roponen M, Remes S, Hirvonen M-R, Pekkanen $\mathrm{J}$ : Exposure to dogs is associated with a decreased tumour necrosis factora-producing capacity in early life. Clin Exp Allergy 2010, 40:1498-1506.

19. Almqvist C, Garden F, Kemp AS, Li Q, Crisafulli D, Tovey ER, Xuan W, Marks GB: Effects of early cat or dog ownership on sensitisation and asthma in a high-risk cohort without disease-related modification of exposure. Paediatr Perinat Epidemiol 2010, 24:171-178.

20. Bufford JD, Reardon CL, Li Z, Roberg KA, DaSilva D, Eggleston PA, Liu AH, Milton D, Alwis U, Gangnon R, Lemanske RF Jr, Gern JE: Effects of dog ownership in early childhood on immune development and atopic diseases. Clin Exp Allergy 2008, 38:1635-1643.

21. Bertelsen RJ, Carlsen KCL, Carlsen K-H, Granum B, Doekes G, Håland G, Mowinckel P, Løvik M: Childhood asthma and early life exposure to indoor allergens, endotoxin and beta(1,3)-glucans. Clin Exp Allergy 2010, 40:307-316.

22. Chan-Yeung M, Hegele RG, Dimich-Ward H, Ferguson A, Schulzer M, Chan $\mathrm{H}$, Watson W, Becker A: Early environmental determinants of asthma risk in a high-risk birth cohort. Pediatr Allergy Immunol 2008, 19:482-489.

23. Lombardi E, Simoni M, La Grutta S, Viegi G, Bisanti L, Chellini E, Dell'Orco V, Migliore E, Petronio MG, Pistelli R, Rusconi F, Sestini P, Forastiere F, Galassi C
Effects of pet exposure in the first year of life on respiratory and allergic symptoms in 7-yr-old children. The SIDRIA-2 study. Pediatr Allergy Immunol 2010, 21:268-276

24. Kerkhof M, Wijga AH, Brunekreef B, Smit HA, de Jongste JC, Aalberse RC, Hoekstra MO, Gerritsen J, Postma DS: Effects of pets on asthma development up to 8 years of age: the PIAMA study. Allergy 2009, 64:1202-1208.

25. Chen C-M, Tischer C, Schnappinger M, Heinrich J: The role of cats and dogs in asthma and allergy-a systematic review. Int J Hyg Environ Health 2010, 213:1-31.

26. Jatakanon A, Lim S, Kharitonov SA, Chung KF, Barnes PJ: Correlation between exhaled nitric oxide, sputum eosinophils, and methacholine responsiveness in patients with mild asthma. Thorax 1998, 53:91-95.

27. Strunk RC, Szefler SJ, Phillips BR, Zeiger RS, Chinchilli VM, Larsen G, Hodgdon K, Morgan W, Sorkness CA, Lemanske RF Jr: Relationship of exhaled nitric oxide to clinical and inflammatory markers of persistent asthma in children. J Allergy Clin Immunol 2003, 112:883-892.

28. Barnes PJ, Dweik RA, Gelb AF, Gibson PG, George SC, Grasemann H, Pavord $I D$, Ratjen F, Silkoff $P E$, Taylor DR, Zamel N: Exhaled nitric oxide in pulmonary diseases: a comprehensive review. Chest 2010, 138:682-692.

29. Dweik RA, Comhair SA, Gaston B, Thunnissen FB, Farver C, Thomassen MJ, Kavuru M, Hammel J, Abu-Soud HM, Erzurum SC: NO chemical events in the human airway during the immediate and late antigen-induced asthmatic response. Proc Natl Acad Sci USA 2001, 98:2622-2627.

30. Van der Valk RJP, Caudri D, Savenije O, Koppelman GH, Smit HA, Wijga AH, Postma DS, Kerkhof M, Brunekreef B, de Jongste JC: Childhood wheezing phenotypes and FeNO in atopic children at age 8. Clin Exp Allergy 2012, 42:1329-1336.

31. Pijnenburg MWH, De Jongste JC: Exhaled nitric oxide in childhood asthma: a review. Clin Exp Allergy 2008, 38:246-259.

32. Moeller A, Diefenbacher C, Lehmann A, Rochat M, Brooks-Wildhaber J, Hall GL, Wildhaber JH: Exhaled nitric oxide distinguishes between subgroups of preschool children with respiratory symptoms. J Allergy Clin Immunol 2008, 121:705-709.

33. Scott M, Raza A, Karmaus W, Mitchell F, Grundy J, Kurukulaaratchy RJ, Arshad SH, Roberts G: Influence of atopy and asthma on exhaled nitric oxide in an unselected birth cohort study. Thorax 2010, 65:258-262.

34. Barraza-Villarreal A, Sunyer J, Hernandez-Cadena L, Escamilla-Nuñez MC, Sienra-Monge JJ, Ramírez-Aguilar M, Cortez-Lugo M, Holguin F, DiazSánchez D, Olin AC, Romieu I: Air pollution, airway inflammation, and lung function in a cohort study of Mexico City schoolchildren. Environ Health Perspect 2008, 116:832-838

35. Lin W, Huang W, Zhu T, Hu M, Brunekreef B, Zhang Y, Liu X, Cheng H, Gehring U, Li C, Tang X: Acute respiratory inflammation in children and black carbon in ambient air before and during the 2008 Beijing Olympics. Environ Health Perspect 2011, 119:1507-1512.

36. Jedrychowski W, Maugeri U, Mroz E, Flak E, Rembiasz M, Jacek R, Sowa A: Fractional exhaled nitric oxide in healthy non-asthmatic 7-year olds and prenatal exposure to polycyclic aromatic hydrocarbons: nested regression analysis. Pediatr Pulmonol 2012, 47:1131-1139.

37. Sordillo JE, Webb T, Kwan D, Kamel J, Hoffman E, Milton DK, Gold DR: Allergen exposure modifies the relation of sensitization to fraction of exhaled nitric oxide levels in children at risk for allergy and asthma. J Allergy Clin Immunol 2011, 127:1165-1172. e5.

38. Kovesi TA, Dales RE: Effects of the indoor environment on the fraction of exhaled nitric oxide in school-aged children. Can Respir J 2009, 16:e18-e23.

39. Heinrich J, Bolte G, Hölscher B, Douwes J, Lehmann I, Fahlbusch B, Bischof W, Weiss M, Borte M, Wichmann HE: Allergens and endotoxin on mothers' mattresses and total immunoglobulin E in cord blood of neonates. Eur Respir J 2002, 20:617-623.

40. Brunekreef B, Smit J, de Jongste J, Neijens H, Gerritsen J, Postma D, Aalberse R, Koopman L, Kerkhof M, Wilga A, van Strien R: The prevention and incidence of asthma and mite allergy (PIAMA) birth cohort study: design and first results. Pediatr Allergy Immunol 2002, 13(Suppl 15):55-60.

41. Torrent M, Sunyer J, Garcia R, Harris J, Iturriaga MV, Puig C, Vall O, Anto JM, Newman Taylor AJ, Cullinan P: Early-life allergen exposure and atopy, asthma, and wheeze up to 6 years of age. Am J Respir Crit Care Med 2007, 176:446-453.

42. Casas L, Tischer C, Wouters IM, Valkonen M, Gehring U, Doekes G, Torrent M, Pekkanen J, Garcia-Esteban R, Hyvärinen A, Heinrich J, Sunyer J: Endotoxin, extracellular polysaccharides, and $\beta(1-3)$-glucan 
concentrations in dust and their determinants in four European birth cohorts: results from the HITEA project. Indoor Air 2013, 23:208-218.

43. Gehring $U$, Oldenwening M, Brunekreef $B$, Wieringa MH, Kerkhof M, Smit HA, van der Ent CK, De Jongste JC: The impact of ambient NO on online measurements of exhaled and nasal NO: the PIAMA study. Pediatr Allergy Immunol 2009, 20:665-672.

44. ATS, ERS: ATS/ERS recommendations for standardized procedures for the online and offline measurement of exhaled lower respiratory nitric oxide and nasal nitric oxide, 2005. Am J Respir Crit Care Med 2005, 171:912-930.

45. Schram D, Doekes G, Boeve M, Douwes J, Riedler J, Ublagger E, von Mutius E, Budde J, Pershagen G, Nyberg F, Alm J, Braun-Fahrländer C, Waser M, Brunekreef $B$ : Bacterial and fungal components in house dust of farm children, Rudolf Steiner school children and reference children-the PARSIFAL Study. Allergy 2005, 60:611-618.

46. Hastie T, Tibshirani R: Generalized additive models for medical research. Stat Methods Med Res 1995, 4:187-196.

47. Gerhold K, Avagyan A, Seib C, Frei R, Steinle J, Ahrens B, Dittrich A-M, Blumchen K, Lauener R, Hamelmann E: Prenatal initiation of endotoxin airway exposure prevents subsequent allergen-induced sensitization and airway inflammation in mice. J Allergy Clin Immunol 2006, 118:666-673.

48. Gerhold K, Avagyan A, Reichert E, Seib C, Van DV, Luger EO, Hutloff A, Hamelmann E: Prenatal allergen exposures prevent allergen-induced sensitization and airway inflammation in young mice. Allergy 2012, 67:353-361.

49. Gereda JE, Leung DY, Thatayatikom A, Streib JE, Price MR, Klinnert MD, Liu AH: Relation between house-dust endotoxin exposure, type $1 \mathrm{~T}$-cell development, and allergen sensitisation in infants at high risk of asthma. Lancet 2000, 355:1680-1683.

50. Campo P, Kalra HK, Levin L, Reponen T, Olds R, Lummus ZL, Cho S-H, Khurana Hershey GK, Lockey J, Villareal M, Stanforth S, Lemasters G, Bernstein DI: Influence of dog ownership and high endotoxin on wheezing and atopy during infancy. J Allergy Clin Immunol 2006, 118:1271-1278.

51. Byrnes CA, Dinarevic S, Shinebourne EA, Barnes PJ, Bush A: Exhaled nitric oxide measurements in normal and asthmatic children. Pediatr Pulmonol 1997, 24:312-318

52. Franklin PJ, Turner SW, Le Souëf PN, Stick SM: Exhaled nitric oxide and asthma: complex interactions between atopy, airway responsiveness, and symptoms in a community population of children. Thorax 2003, 58:1048-1052

53. Morgan WJ, Stern DA, Sherrill DL, Guerra S, Holberg CJ, Guilbert TW, Taussig LM, Wright AL, Martinez FD: Outcome of asthma and wheezing in the first 6 years of life: follow-up through adolescence. Am J Respir Crit Care Med 2005, 172:1253-1258

54. Savenije OE, Granell R, Caudri D, Koppelman GH, Smit HA, Wijga A, de Jongste JC, Brunekreef B, Sterne JA, Postma DS, Henderson J, Kerkhof M: Comparison of childhood wheezing phenotypes in 2 birth cohorts: ALSPAC and PIAMA. J Allergy Clin Immunol 2011, 127:1505-1512. e14.

55. Dweik RA, Boggs PB, Erzurum SC, Irvin CG, Leigh MW, Lundberg JO, Olin A-C, Plummer AL, Taylor DR: An official ATS clinical practice guideline: interpretation of exhaled nitric oxide levels (FENO) for clinical applications. Am J Respir Crit Care Med 2011, 184:602-615.

56. Teague WG: Exhaled nitric oxide in wheezy infants: a marker of inflammation determined by airways acidification and S-nitrosothiol degradation? J Allergy Clin Immunol 2010, 125:1235-1236.

57. Dweik RA, Sorkness RL, Wenzel S, Hammel J, Curran-Everett D, Comhair SAA Bleecker E, Busse W, Calhoun WJ, Castro M, Chung KF, Israel E, Jarjour N, Moore W, Peters S, Teague G, Gaston B, Erzurum SC: Use of exhaled nitric oxide measurement to identify a reactive, at-risk phenotype among patients with asthma. Am J Respir Crit Care Med 2010, 181:1033-1041.

doi:10.1186/1476-069X-12-103

Cite this article as: Casas et al:: Early life microbial exposure and fractional exhaled nitric oxide in school-age children:

a prospective birth cohort study. Environmental Health 2013 12:103.

\section{Submit your next manuscript to BioMed Central and take full advantage of:}

- Convenient online submission

- Thorough peer review

- No space constraints or color figure charges

- Immediate publication on acceptance

- Inclusion in PubMed, CAS, Scopus and Google Scholar

- Research which is freely available for redistribution
C Biomed Central 